\title{
A Novel Penile Splint as Early Traction Therapy After Grafting
}

\section{Techniques for Peyronie's Disease}

\section{ABSTRACT}

Background: Some studies showed encouraging results on the efficacy and safety of penile traction therapy (PTT) after Peyronie's disease (PD) surgery. The early traction therapy (ETT) could be an effective and safe approach to minimize penile shortening in patients undergoing PD surgery.

Aim: To evaluate the feasibility, efficacy, and safety of a novel penile splint as ETT in PD patients undergoing grafting techniques.

Methods: PD patients underwent plaque incision and grafting (PIG) technique, at the end of the procedure a novel penile splint (ETT) was applied to all patient. The device consisted of two 10Ch intubating stylets, self-adapted to each patient, that kept the penis stretched with the aid of nonabsorbable sutures. The total expense for the materials needed to build each penile splint was less than 15 euros. This active traction was maintained for 1-3weeks, then we removed the stitches leaving the device on-site for a passive traction. Within 3-4 weeks from surgery, the penile splint was replaced by a standard penile traction device.

Outcomes: The main outcomes evaluated at 6 months included stretched penile length (SPL), penile curvature, International Index of Erectile Function - Erectile Function domain (IIEF-EF), patient satisfaction, and time to first satisfactory sexual intercourse.

Results: A total of 46 patients were enrolled. The median preoperative IIEF-EF, penile curvature, and SPL were 27 points, 70 degrees, and $13 \mathrm{~cm}$. The median follow-up was 15 months. The median postoperative IIEF-EF was 25 points $(\mathrm{p}<0.001)$. The median residual penile curvature was 10 degrees $(\mathrm{p}<0.001)$. The median postoperative SPL was $13 \mathrm{~cm}(\mathrm{p}=0.269)$. Eight patients $(17.4 \%)$ lose $1 \mathrm{~cm}$ of SPL, no shortening greater than $1 \mathrm{~cm}$ was recorded. The median time to first satisfactory sexual intercourse and patient satisfaction score was 6 weeks and 9 points, respectively.

Clinical Implications: Our results could pave the way for a new line of research, which in turn could lead to an improvement in the postoperative management of the patient undergoing surgery for PD.

Strength \& Limitations: This is the first study evaluating the ETT after PD surgery. The main limitation of this study is the lack of a randomized control group. Other weaknesses are the small sample size and the short follow-up time.

Conclusion: Our novel penile splint is inexpensive, easy to assemble, and adaptable to the patient. ETT using this novel device, followed by standard traction therapy, seems to be feasible, effective, and safe. 


\section{Introduction}

Tunical lengthening procedures are the gold standard treatment for Peyronie's disease (PD) patients, in stable phase of disease, with severe curvature, short penis, or complex deformities, without erectile dysfunction. ${ }^{1}$ These procedures are performed on the concave side of the penis and consist of making an incision or partial excision of the plaque, and covering the defect with a graft. $^{2}$ The tunical lengthening techniques aim to minimize the penile shortening, nevertheless, a significant reduction in length of penis was described by several authors. ${ }^{3,4}$ The current European Association of Urology (EAU) Guidelines recommend the use of penile traction therapy (PTT), as conservative treatment of PD, alone or in combination with other procedures, although outcome data are limited. ${ }^{1,5}$ The clinical goals of PTT are to reduce curvature, enhance circumference, and recover lost length, causing only limited adverse events (AE). Several studies showed encouraging results on the efficacy and safety of PTT in both the acute and chronic phase of PD, as well as after PD surgery. ${ }^{6-8}$

The penile splint is a device, generally assembled by the surgeon and applied at the end of the penile surgery, which aims to improve the surgical outcomes. ${ }^{9-13}$

\section{Rationale and Aim}

The early traction therapy (ETT), applied immediately at the end of the surgical procedure, could be an effective and safe approach to minimize penile shortening in patients undergoing PD surgery. The aim of the present study is to evaluate the feasibility, efficacy, and safety of a novel penile splint as ETT in PD patients undergoing grafting techniques.

\section{Indications for procedure}

Patients with stable PD for at least 3 months, normal erectile function with or without pharmacological treatment, any type of penile curvature $>60^{\circ}$ and/or no adequate penile length and/or complex deformities (hourglass, hinge), undergoing grafting technique, were included in the study. Active infectious diseases and suspect of penile tumor were exclusion criteria. Calcified plaques were not an exclusion criterion. All patients in whom a reduction of the penile length of at least $2 \mathrm{~cm}$ with shortening procedures was expected were considered to have a no adequate penile length.

\section{Patients' recruitment and assessment}


Patients of the present study were recruited from February 2017 to July 2019. All subjects were informed about the surgical procedure and provided a written informed consent. Each patient enrolled underwent medical and sexual history as well as a physical examination. The short version of the International Index of Erectile Function for the evaluation of the erectile function $(\text { IIEF-EF) })^{14}$ and the Peyronie's Disease Questionnaire (PDQ) ${ }^{15}$ were self-administrated to patients. The penile curvature was evaluated with the Kelami method. ${ }^{16}$ The stretched penile length (SPL) was assessed by a urologist using a tape measure, from the base (pubo-penile junction) to the tip of the glans (meatus) on the dorsal aspect of the penis. The study of penile plaques was performed with ultrasonography by a radiologist.

\section{Statistics}

We used the median as a measure of central tendency and the interquartile range (IQR) as a measure of statistical dispersion. The Wilcoxon Signed-Ranks Test was used to analyze the data. All tests were two-sided with a significance set at $\mathrm{p}<0.05$. IBM SPSS Statistics® (IBM Corp. Released 2017. IBM SPSS Statistics for Windows, Version 25.0. Armonk, NY: IBM Corp.) was used for the statistical analyses.

\section{Pre-operative preparation}

Patients were placed in supine position and washed with chlorhexidine gluconate (CHG) soap. Intravenous sedation with local anesthesia, as well as preoperative single-dose of cefazolin, were administered to all patients.

\section{Intraoperative consideration}

A Gittes test ${ }^{17}$ was performed with intracavernous saline injection to evaluate penile curvature degree and any other deformities. All patients underwent plaque incision and grafting (PIG) technique with TachoSil ${ }^{\circledR}$ (Baxter, CA, USA). In all cases the whole graft $(9.5 \times 4.8 \mathrm{~cm})$ was used to cover the tunical defect. Each subject underwent circumcision, while none received the implantation of a penile prosthesis. All surgeries were performed by a single experienced surgeon in an ambulatory center. At the end of the procedures, the penile splint (ETT) was applied to all patient by the surgeon, adapting it based on penile size (length and girth).

\section{Penile splint: assembly and cost}

First of all, the penis was wrapped with a cotton wool roll to protect the skin from pressure ulcers. Then, two 10Ch intubating stylets (Shiley ${ }^{\mathrm{TM}} / \mathrm{Mallinckrodt}^{\mathrm{TM}}$, Medtronic, MN, USA) 
(Figure 1) were positioned vertically and fixed to penile skin with two $1 / 0$ polypropylene sutures (at 3-o'clock and 9-o'clock) (Figure 2). Lastly, an elastic bandage was applied, and the distal parts of the stylets were bent (Figure 3) to improve patient comfort. The assembly time was always less than 5 minutes. The cost of each stylet was less than 5 euros, and the total expense for the materials needed to build each penile splint was less than 15 euros.

\section{Post-operative management and follow-up}

Patients were discharged with penile splint in the two-three hours after the procedure, being instructed to maintain the device until the next revision. No antibiotic was prescribed, while common analgesics as needed was allowed.

Until January 2018, we maintained the active traction (device with stitches) for 2-3 weeks, subsequently, due to observed discomfort and pain of the patients, we reduced this time to 7 days. Once these first days of active traction were over, we removed the stitches leaving the device on-site (passive traction) until 3-4 weeks after surgery. Wound cleaning and dressing changes were performed every 7 days. In all patients, after this period, when the circumcision was healed, the penile splint was replaced by a standard penile traction device (Andropeyronie ${ }^{\circledR} /$ Andropenis $^{\circledR}$, Andromedical SL, Madrid, Spain) for at least 4-6 months with intensive daily use (at least 3 hours a day).

After 6 months from surgery, changes in penile curvature, SPL, and IIEF-EF, as well as time to first satisfactory sexual intercourse and patient satisfaction on a scale of 0 to $10,{ }^{18}$ were assessed. All observed AE during the study period were recorded.

\section{Outcomes and Complications}

A total of 46 patients, with a median (IQR) age of 55 (45.5-61.3) years, were enrolled in the study. The median (IQR) preoperative IIEF-EF, penile curvature, and SPL were 27 (24-29) points, $70(60-81.3)$ degrees, and $13(12-15) \mathrm{cm}$, respectively. Only 3 patients $(6.5 \%)$ took an intermediate dosage of Phosphodiesterase-5 (PDE5) inhibitors before the surgery. The baseline characteristics of patients are reported in Table 1.

The median (IQR) operative time and follow-up were 80 (70-90) minutes and 15 (11.3-24) months, respectively. Twenty-eight patients (60.9\%) used the early active traction for 7 days, while only 7 subjects $(15.2 \%)$ for more than 2 weeks. The median (IQR) time of early active traction was 7 (7-14) days.

The median (IQR) postoperative IIEF-EF was $25(22-27)$ points $(\mathrm{p}<0.001), 13$ patients $(28.3 \%)$ worsened this score and reached the minimal clinically important difference (MCID) 
after the surgery. ${ }^{19}$ The median (IQR) residual penile curvature was 10 (5-10) degrees, with a statistically significant difference from the baseline $(\mathrm{p}<0.001)$. Ten patients $(21.7 \%)$ at 6 months of follow-up used PDE5 inhibitors, however only 6 subjects really needed it as they were unable to have a satisfactory intercourse, another 4 did not want to interrupt the treatment because they noticed an improvement in erectile function compared to their condition before surgery. Eight patients (17.4\%) had a residual curvature of 15 degrees, and no subject exceeded this value. The median (IQR) postoperative SPL was $13(12.8-15) \mathrm{cm}$, without a significant difference from the baseline $(\mathrm{p}=0.269)$. Only 8 patients $(17.4 \%)$ lose $1 \mathrm{~cm}$ of SPL, no shortening greater than $1 \mathrm{~cm}$ was recorded in any subject, the median difference of postsurgicalSPL and presurgical-SPL was $0 \mathrm{~cm}$. A statistically significant $(\mathrm{p}<0.001)$ postoperative improvement of all PDQ domains was reported. The median (IQR) time to first satisfactory sexual intercourse and patient satisfaction score was 6 (5-8) weeks and 9 (8-9) points, respectively. Patients did not report any changes between the 6-month visit and the end of the follow-up. The postoperative outcomes are reported in Table 2. No intraoperative complications occurred. Five cases $(10.9 \%)$ of postoperative hematoma and 2 cases $(4.3 \%)$ of glans numbness at 6-months follow-up visit was recorded. No severe complications (ClavienDindo III-V $)^{20}$ were revealed, in particular, only grade I adverse events occurred during the study. There was no fall or movement of the dressing that required its repositioning, this was favored in the first weeks by the presence of the sutures that fixed the entire device to the penile skin. Only 3 patients $(6.5 \%)$ required removal of the bandage due to excessive compression, however the penile splint was maintained by replacing only the dressing.

\section{Brief Literature Review and Discussion of Results}

Currently, there are no studies investigating assessing the ETT after PD surgery, as well as there are no papers evaluating the use of a penile splint as traction therapy in PD setting.

Only two articles investigated the role of PTT after PD surgery, ${ }^{21,22}$ however, in both studies the traction was not applied immediately after the end of the surgery, but several weeks later. Moncada-Iribarren et al. ${ }^{21}$ reported the use of a traction device (Andropenis ${ }^{\circledR}$, Andromedical SL, Madrid, Spain) after penile grafting or plication. PTT was applied when the circumcision had healed ( 2 to 3 weeks after surgery), 8 to 12 hours daily during at least 4 months. A total of 40 men who had PD surgery (12 men with penile grafting and 28 men with penile plication) were randomized (20:20) to PTT vs observation. Globally, penile shortening after surgery ranged from 0.5 to $4.0 \mathrm{~cm}$. SPL of the patients in the PTT group increased ranging from 1 to 3 $\mathrm{cm}$, and the increase was proportional to the number of hours per month of PTT use. 
Rybak et al. ${ }^{22}$ reported in a nonrandomized retrospective study the use of a traction device (USPhysioMED Penile Extender ${ }^{\circledR}$, USPhysioMED, Aliso Viejo, CA, USA) after penile plication or partial plaque excision and grafting. PTT was recommended for 2-6 hours a day for 3 months, typically starting 3-4 weeks postoperatively. In total 27/52 plication patients and 36/59 PEG patients performed PTT. Patients who performed PTT had a significantly greater mean increase in SPL (compared with preoperative measurements) compared to the patient without traction. This was true for both the plication group $(+0.85 \mathrm{~cm}$ vs $-0.53 \mathrm{~cm} ; \mathrm{p}<0.001)$ and the graft group $(+1.48 \mathrm{~cm}$ vs $+0.24 \mathrm{~cm} ; \mathrm{p}<0.001)$.

Several studies evaluated the use of penile splints in the last few decades. ${ }^{9-13}$ These devices were built by the surgeon and applied at the end of the surgical procedure. They were generally real craft products assembled with easily available materials such as plastic bottles, thermocol glasses, plastic syringes, or gauzes. ${ }^{10-13}$ The purpose of penile splints was to achieve a compressive effect, or keep the penis in a specific position or stretched, in order to reduce edema or improve the wound healing after surgery. ${ }^{9,11,13}$ Despite the abundance of studies on the topic present in the literature, the overall quality of them is low due to major methodological issues, including the lack of use of standardized outcome measures, with results reported in qualitative rather than quantitative form.

The penile shortening described in other PIG series reflects, in most cases, the occurrence of a graft contraction. ${ }^{23-29}$ In a recent review of Rice et al. ${ }^{4}$ was reported that between $4.9 \%$ and $40.0 \%$ of patients experienced shortening of penis after PIG. The use of our novel penile splint seems to prevent the graft shrinkage during the initial healing phase, and subsequent standard traction therapy strengthens the graft stretching, this could favor the preservation of the penile length after surgery. On the other hand, the low incidence of hematomas in our study, probably due to the maintenance of the bandage for a longer period of time, could promote the early recovery of sexual activity.

\section{Strength and Limitations of Our Results}

Despite abundant literature on PTT in PD patients, this is the first study evaluating the feasibility, efficacy, and safety of ETT after PD surgery. Our encouraging results could pave the way for a new line of research regarding this topic, which in turn could lead to an improvement in the postoperative management of the patient undergoing surgery for PD.

The main limitation of this study is the lack of a randomized control group. Other weaknesses are the small sample size and the short follow-up time. 


\section{Take-home message}

ETT using our novel penile splint, followed by standard traction therapy, seems to be feasible, effective, and safe. The device is inexpensive, easy to assemble, and adaptable to the patient. No significant penile shortening, an early recovery of satisfactory sexual activity, as well as no severe AE, can be obtained with its use. However, randomized controlled trials, with large sample size and long follow-up, are needed to confirm these preliminary results and to define the most appropriate duration of early traction.

\section{References}

1 Salonia A, Bettocchi C, Carvalho J, et al. EAU Guidelines on Sexual and Reproductive Health. In: European Association of Urology Guidelines. Arnhem, Netherlands, 2020.

2 Hatzichristodoulou G, Tsambarlis P, Kübler H, Levine LA. Peyronie's graft surgerytips and tricks from the masters in andrologic surgery. Transl Androl Urol 2017; 6: 645-56.

3 Garcia-Gomez B, Ralph D, Levine L, et al. Grafts for Peyronie's disease: a comprehensive review. Andrology 2018; 6: 117-26.

4 Rice PG, Somani BK, Rees RW. Twenty Years of Plaque Incision and Grafting for Peyronie's Disease: A Review of Literature. Sex Med 2019; 7: 115-28.

5 Cocci A, Cito G, Urzì D, et al. Sildenafil 25 mg ODT + Collagenase Clostridium hystoliticum vs Collagenase Clostridium hystoliticum Alone for the Management of Peyronie's Disease: A Matched-Pair Comparison Analysis. J Sex Med 2018; 15: $1472-$ 7.

6 Bole R, White L, Parikh N, Helo S, Kohler T, Ziegelmann M. A modern review of penile traction monotherapy and combination therapy for the treatment of peyronie's disease. Int J Impot Res 2020.

7 Martínez-Salamanca JI, Egui A, Moncada I, et al. Acute phase peyronie's disease management with traction device: A nonrandomized prospective controlled trial with ultrasound correlation. J Sex Med 2014; 11: 506-15.

8 Moncada I, Krishnappa P, Romero J, et al. Penile traction therapy with the new device 'Penimaster PRO' is effective and safe in the stable phase of Peyronie's disease: a controlled multicentre study. BJU Int 2019; 123: 694-702.

9 Ferguson REH, Schaeffer CS. A Simple Bolstering Method For Optimizing Skin Graft Take On The Shaft Of The Penis. Plast Reconstr Surg 2005; 116: 1835-6. 
10 Sharma A, Misra A, Basu S. Splinting of penis following microvascular reconstruction- A simple inexpensive method. Indian J Plast Surg 2009; 42: 245-7.

11 Ahmad M, Shahid Hussain S, Malik SA. Use of a plastic syringe as a splint after penile surgery. J Plast Reconstr Aesthetic Surg 2010; 63: e231.

12 Lippin Y, Shvoron A, Tsur H. A Simple Splinting Device for Skin Grafts of the Penis. Ann Plast Surg 1992; 29: 185-6.

13 Anderson KA, McAninch JW. Penile dressing splint. Urology 1982; 20: 188.

14 Cappelleri JC, Rosen RC, Smith MD, Mishra A, Osterloh IH. Diagnostic evaluation of the erectile function domain of the International Index of Erectile Function. Urology 1999; 54: 346-51.

15 Hellstrom WJG, Feldman R, Rosen RC, Smith T, Kaufman G, Tursi J. Bother and distress associated with peyronie's disease: Validation of the peyronie's disease questionnaire. J Urol 2013; 190: 627-34.

16 Kelâmi A. Classification of congenital and acquired penile deviation. Urol Int 1983; 38: 229-33.

17 Gittes RF, McLaughlin AP. Injection technique to induce penile erection. Urology 1974; 4: 473-4.

18 Junewicz A, Youngner SJ. Patient-satisfaction surveys on a scale of 0 to 10: Improving health care, or leading it astray? Hastings Cent Rep 2015; 45: 43-51.

19 Rosen RC, Allen KR, Ni X, Araujo AB. Minimal clinically important differences in the erectile function domain of the international index of erectile function scale. Eur Urol 2011; 60: 1010-6.

20 Dindo D, Demartines N, Clavien PA. Classification of surgical complications: A new proposal with evaluation in a cohort of 6336 patients and results of a survey. Ann Surg 2004; 240: 205-13.

21 Moncada-Iribarren I, Jara J, Martinez-Salamanca JI, Cabello R, Hernandez C. Managing Penile Shortening after Peyronie's Disease Surgery. J Urol 2007; 177: 252 252.

22 Rybak J, Papagiannopoulos D, Levine L. A Retrospective Comparative Study of Traction Therapy vs. No Traction Following Tunica Albuginea Plication or Partial Excision and Grafting for Peyronie's Disease: Measured Lengths and Patient Perceptions. J Sex Med 2012; 9: 2396-403.

23 Akkus E, Ozkara H, Alici B, et al. Incision and venous patch graft in the surgical treatment of penile curvature in Peyronie's disease. Eur Urol 2001; 40: 531-7. 
24 Chung E, Clendinning E, Lessard L, Brock G. Five-Year Follow-Up of Peyronie's Graft Surgery: Outcomes and Patient Satisfaction. J Sex Med 2011; 8: 594-600.

25 El-Sakka A, Rashwan H, Lue T. Venous patch graft for peyronie's disease. Part I: Technique. J Urol 1998; 160: 2047-9.

26 Kalsi J, Minhas S, Christopher N, Ralph D. The results of plaque incision and venous grafting (Lue procedure) to correct the penile deformity of Peyronie's disease. BJU Int 2005; 95: 1029-33.

27 Knoll LD. Use of Small Intestinal Submucosa Graft for the Surgical Management of Peyronie's Disease. J Urol 2007; 178: 2474-8.

28 Montorsi F, Salonia A, Maga T, et al. Evidence based assessment of long-term results of plaque incision and vein grafting for Peyronie's disease. J Urol 2000; 163: 1704-8.

29 Sayedahmed K, Rosenhammer B, Spachmann PJ, et al. Bicentric prospective evaluation of corporoplasty with porcine small intestinal submucosa (SIS) in patients with severe Peyronie's disease. World J Urol 2017; 35: 1119-24. 
Tables

Table 1. Baseline characteristics of patients

\begin{tabular}{|c|c|}
\hline Subjects, $n$ & 46 \\
\hline $\begin{array}{l}\text { Age, years } \\
\text { median (IQR) }\end{array}$ & $55(45.5-61.3)$ \\
\hline $\begin{array}{l}\text { Time from onset of disease, } \text { months } \\
\text { median (IQR) }\end{array}$ & $18(14-24)$ \\
\hline $\begin{array}{l}\text { Penile curvature } \\
\text { - Angle, degrees } \\
\text { median (IQR) }\end{array}$ & $70(60-81.3)$ \\
\hline - Direction & \\
\hline$\circ$ Dorsal, $n(\%)$ & $31(67.4)$ \\
\hline$\circ \quad$ Lateral, $n(\%)$ & $9(19.6)$ \\
\hline$\circ$ Dorsolateral, $n(\%)$ & $6(13.0)$ \\
\hline$\circ \quad$ Ventral, $n(\%)$ & $0(0)$ \\
\hline - Complex deformities & \\
\hline ○ Hourglass, $n(\%)$ & $7(15.2)$ \\
\hline$\circ \quad$ Hinge, $n(\%)$ & $10(21.7)$ \\
\hline
\end{tabular}

IQR: interquartile range.

Table 2. Postoperative outcomes

\begin{tabular}{|l|l|l|l|}
\hline & Baseline & $\begin{array}{l}\text { At 6 months } \\
\text { from surgery }\end{array}$ & p \\
\hline $\begin{array}{l}\text { Penile curvature, degrees } \\
\text { median (IQR) }\end{array}$ & $70(60-81.3)$ & $10(5-10)$ & $<0.001$ \\
\hline $\begin{array}{l}\text { SPL, } \mathrm{cm} \\
\text { median (IQR) }\end{array}$ & $13(12-15)$ & $13(12.8-15)$ & 0.269 \\
\hline IIEF-EF, points & $27(24-29)$ & $25(22-27)$ & $<0.001$ \\
\hline
\end{tabular}




\begin{tabular}{|c|l|l|l|}
\hline median (IQR) & & & \\
\hline $\begin{array}{c}\text { PDQ } \\
\text { median (IQR) }\end{array}$ & $11(9-13.3)$ & $2(0-4.3)$ & $<0.001$ \\
$\begin{array}{c}\text { PDQ-PP, points } \\
\text { median (IQR) }\end{array}$ & $3(0.8-6)$ & $0(0-0.8)$ & $<0.001$ \\
$\quad$ PDQ-PS, points & $15(10-18.5)$ & $3(2-6)$ & $<0.001$ \\
\hline $\begin{array}{l}\text { Patient satisfaction, points } \\
\text { median (IQR) }\end{array}$ & NA & $9(8-9)$ & NA \\
\hline $\begin{array}{l}\text { Time to first satisfactory } \\
\text { sexual intercourse, weeks } \\
\text { median (IQR) }\end{array}$ & NA & $6(5-8)$ & NA \\
\hline
\end{tabular}

SPL: stretched penile length; IIEF-EF: International Index of Erectile Function - Erectile Function domain; PDQ: Peyronie's Disease Questionnaire; PDQ-SB: PDQ-Symptom Bother; PDQ-PP: PDQ-Penile Pain; PDQ-PS: PDQ-Psychological and Physical Symptoms; IQR: interquartile range; NA: Not Available.

\section{Figures}

Figure 1. 10Ch intubating stylets (Mallinckrodt ${ }^{\mathrm{TM}}$, Medtronic, MN, USA) 


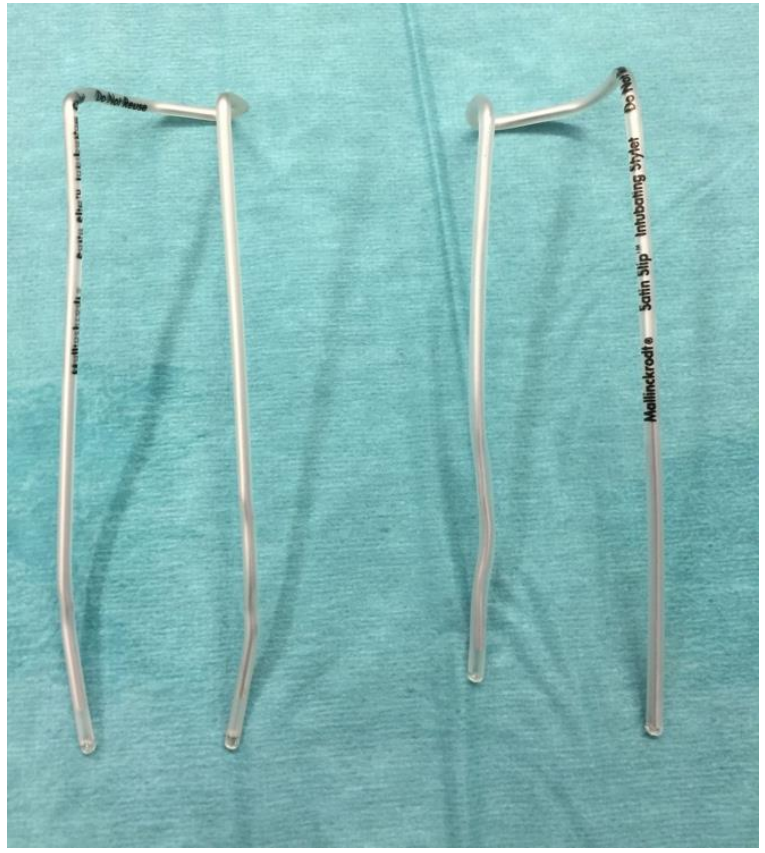

Figure 2. Assembly of the penile splint

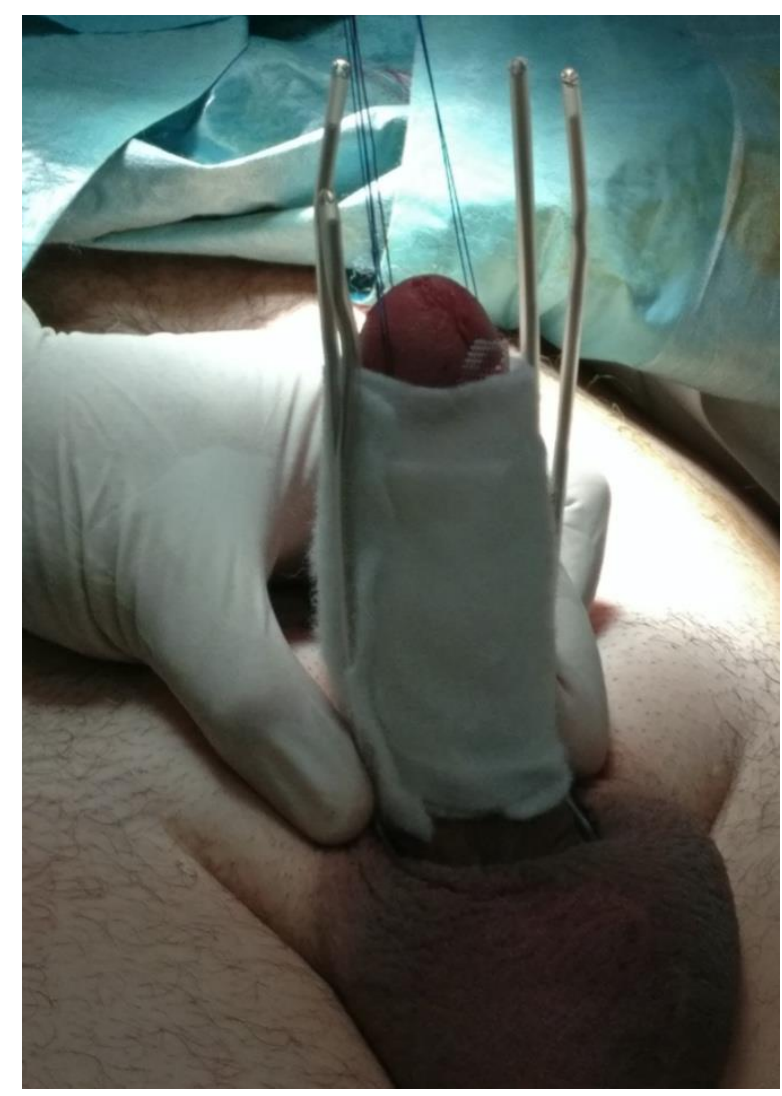

Figure 3. Aspect of the assembled penile splint 


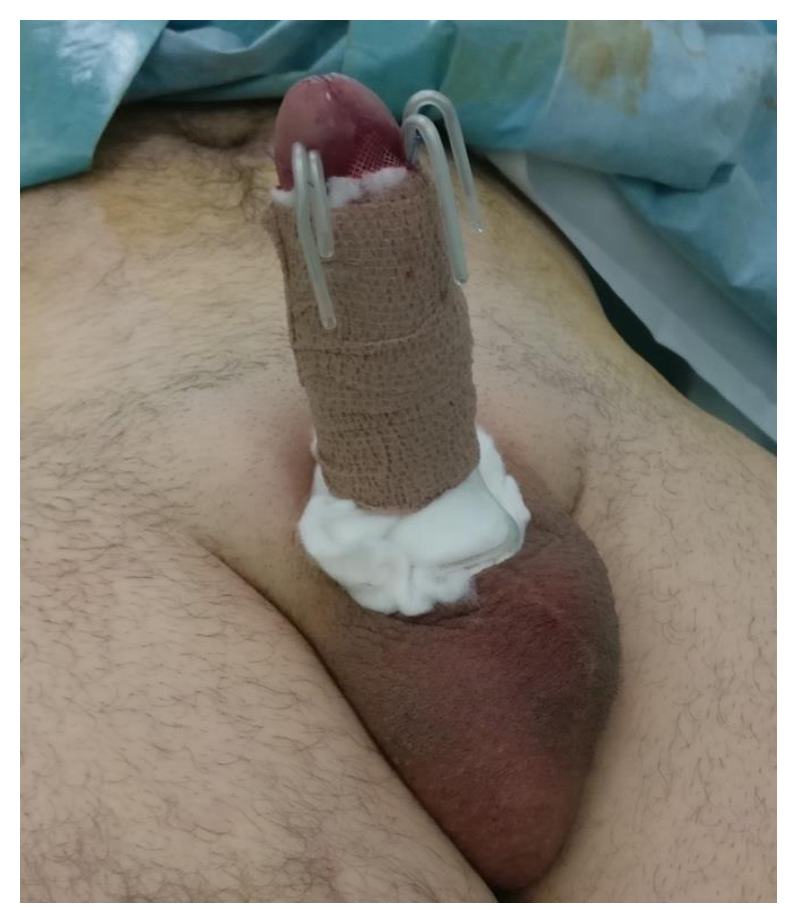

